Revista em Agronegócio e Meio Ambiente, Maringá (PR)

DOI: http://dx.doi.org/10.17765/2176-9168.2018v11n1p327-341

\title{
REFLEXÕES SOBRE ARBORIZAÇÃO URBANA: DESAFIOS A SEREM SUPERADOS PARA O INCREMENTO DA ARBORIZAÇÃO URBANA NO BRASIL
}

\author{
Taíse Ernestina Prestes Nogueira Duarte* \\ Fábio Angeoletto* \\ Jeater Waldemar Maciel Correa Santos*** \\ Frederico Fonseca da Silva**** \\ João Fernando Copetti Bohrer***** \\ Leticia Massad ${ }^{* * * * * *}$
}

RESUMO: Ao propor uma reflexão sobre a arborização urbana no Brasil, o presente artigo pretende, por meio de uma análise histórica e atual, compreender quais os reais desafios a serem superados para valorização e incremento da arborização urbana no Brasil. Dentre os elementos atuantes na desvalorização da arborização urbana no Brasil, o presente artigo aponta o modelo de urbanização inspirado pela colonização portuguesa, bem como a falta de conhecimento sobre os benefícios que a arborização representa para a qualidade ambiental urbana. Ainda, o artigo aponta que a falta de infraestrutura urbana para a população mais pobre atua como um intensificador da desigualdade social no Brasil. Da mesma forma, a falta de estrutura e corpo técnico especializado em muitas prefeituras dificultam as ações de fiscalização, fazendo com que as leis referentes à arborização urbana não sejam de fato aplicadas.

PALAVRAS-CHAVE: Arborização urbana; Qualidade ambiental; Injustiça ambiental.

Acadêmica do Mestrado em Geografia da Universidade Federal de Mato Grosso - UFMT, campus de Rondonópolis, Brasil.

** Docente do Mestrado em Geografia da Universidade Federal de Mato Grosso - UFMT, campus de Rondonópolis, Brasil

*** Docente do Mestrado em Geografia da Universidade Federal de Mato Grosso - UFMT, campus de Rondonópolis, Brasil.

**** Docente e Pesquisador do Instituto Federal do Paraná (IFPR). Doutor em Irrigação e Meio ambiente pela UEM, Brasil.

*****Acadêmico do Mestrado em Geografia da Universidade Federal de Mato Grosso - UFMT, campus de Rondonópolis

******Acadêmica do curso de graduação em Biologia da Universidade Federal de Mato Grosso - UFMT, campus de Rondonópolis, Brasil. E-mail: fabio_angeoletto@yahoo.es 


\section{URBAN ARBORIZATION: CHALLENGES THAT SHOULD BE FACED TO INCREASE THE PLANTING OF TREES IN BRAZILIAN TOWNS}

ABSTRACT: An analysis on urban arborization in Brazil comprises a historical and contemporary study to discover the true challenges that should be overcome for its valorization and increase. Current paper discusses factors that devalue urban arborization due to the city models introduced during the Portuguese colonial period and the lack of knowledge on its benefits for environmental quality. The lack of urban infrastructure for low income populations increases social inequality in Brazil. Lack of a technical team in many towns makes difficult surveillance. Consequently, laws on urban arborization are not enforced.

KEY WORDS: Urban arborization; Environmental quality; Environmental injustice.

\section{INTRODUÇÃO}

Atualmente, estima-se que $67 \%$ da população mundial vivem em áreas urbanas. Nos países desenvolvidos, projeta-se que até 2050 o percentual de população, vivendo em áreas urbanas, alcance 86\% (CRETELLA; BUENGER, 2016). $\mathrm{Na}$ América Latina, uma das regiões mais urbanizadas do globo, com diversas cidades entre as mais populosas do mundo, estima-se que cerca de $80 \%$ da população vivem em cidades, esperando-se que este percentual alcance os 90\% até 2025 (SECRETARIAT OF THE CONVENTION BIOLOGICAL DIVERSITY, 2012). No Brasil, o percentual da população urbana já chega a 83\%. (ANGEOLETTO et al., 2016).

Diante das atuais tendências de expansão urbana, estima-se que até 2030 as áreas urbanizadas sofrerão aumento entre 800 mil e 3,3 milhões de quilômetros quadrados, o que representaria de duas a cinco vezes a área ocupada em 2000, incorporando 60\% de novas áreas (SECRETARIAT OF THE CONVENTION BIOLOGICAL DIVERSITY, 2012). Do ponto de vista ambiental, este aumento das áreas urbanizadas projetado para as próximas décadas representa uma série de impactos significativos à qualidade ambiental urbana como aumento da impermeabilização do solo, aumento das emissões de gases tóxicos, aumento da produção de resíduos sólidos, aumento da temperatura e o risco de enchentes (MAZETTO, 2000; ARIZA; 
SANTOS, 2008; MINAKI; AMORIN, 2012; LOCKE; BAINE, 2015).

A qualidade ambiental caracteriza-se pela interação de diversas variáveis capazes de proporcionar a formação de um habitat salubre, confortável e capaz de satisfazer os requerimentos básicos de sustentabilidade da vida humana (VELÁZZUEZ; CELEMÍN, 2010). Portanto, a arborização urbana é considerada por diversos autores, como o principal indicador de qualidade ambiental urbana, pelos benefícios que ela oferece para o equilíbrio ambiental, saúde e bem-estar da população urbana (MOTA, 1999; MAZETTO, 2000; GOMES; SOARES, 2004; ARIZA; SANTOS, 2008; NUCCI, 2008; MINAKI; AMORIM, 2012; SOUZA; AMORIM, 2016).

O termo "Arborização Urbana” foi inicialmente utilizado no Brasil em tradução ao termo "Urban Forest" utilizado por autores norte-americanos. Entretanto, este termo passou a ser amplamente utilizado no Brasil como sinônimo de arboricultura, ou seja, para designar o ato ou ação de plantar árvores em ambientes urbanos, dissociando-se do conceito original de florestas urbanas (MAGALHÃES, 2006).

De acordo com a Embrapa (2002), a arborização urbana pode ser compreendida como toda a cobertura vegetal de porte arbóreo existente nas cidades, compreendendo as áreas livres de uso público e potencialmente coletivas, áreas livres particulares e acompanhamento do sistema viário. Portanto, o conceito de arborização urbana inclui a cobertura vegetal urbana de porte arbóreo, de origem natural ou não.

A importância da arborização urbana se dá em função dos serviços ecossistêmicos que ela desempenha, capazes de aumentar a biodiversidade, melhorar a qualidade do ar, diminuir os riscos de inundaçóes, proporcionar maior conforto térmico, diminuir a utilização de climatização artificial, proporcionar consequências positivas à saúde humana e, consequentemente, melhorar a qualidade de vida nas áreas urbanas (NUCCI; CAVALHEIRO, 1999; SAMPAIO, 2006; DUARTE et al, 2008; TIAN; TAO; SHI, 2011; ALVES, 2012; SECRETARIAT OF THE CONVENTION ON BIOLOGICAL DIVERSITY, 2012; LOCKE et al., 2013; RAHMAN; ARMSON; ENNOS, 2014; CUBINO; LOZANO; SUBIRÓS, 2015; ALBUQUERQUE; LOPES, 2016; LOURENÇO et al., 2016).

A arborização urbana pode auxiliar na mitigação da sobrecarga dos sistemas de drenagem decorrente da impermeabilização do solo pelo processo de 
urbanização. De acordo com a Secretariat of the Convention on Biological Diversity (2012), as áreas com superfície intensamente impermeabilizadas perdem em torno de 40 a 83\% de água da chuva para o escoamento superficial, enquanto que as áreas vegetadas perdem apenas $13 \%$ em eventos de semelhante precipitação.

Dentre os benefícios da arborização urbana, cabe mencionar a valorização visual e ornamental, estabelecendo uma escala intermediária entre a paisagem natural e a construída (NUCCI; CAVALHEIRO, 1999). Tian et al. (2011) apontam que o contato com os espaços arborizados pode diminuir precursores psicológicos da violência como a irritabilidade, além de reduzir a ansiedade, incrementar o relaxamento e reduzir o estresse, proporcionando benefícios à qualidade de vida da população urbana.

Fatores importantes para a qualidade de vida urbana como o conforto térmico, por exemplo, está diretamente relacionado às condições ambientais, tais como a temperatura, a umidade do ar e ação dos ventos. Assim, o processo de urbanização altera drasticamente as condições ambientais estabelecidas, refletindo-se no comprometimento da qualidade ambiental urbana (ALVES, 2012; ALBUQUERQUE; LOPES, 2016).

Muito embora a degradação da qualidade ambiental, considerada por diversos autores como a maior consequência socioambiental da atualidade, esteja bastante atrelada à urbanização, na verdade, estas consequências estão muito mais ligadas à falta de planejamento urbano do ponto de vista ambiental (GOMES; SOARES, 2004; MINAKI; AMORIM, 2012; ANGEOLETTO; SANTOS, 2015). Portanto, a expansão das áreas urbanas deve valorizar e incrementar a arborização urbana, como forma de compensação da perda de qualidade ambiental ocorrida no processo de produção do espaço.

Diante do crescente aumento das áreas urbanizadas esperados para o presente século, a vegetação urbana ganha ainda mais importância, não só pelos benefícios relacionados à saúde e bem-estar da população, mas pela sua capacidade de mitigar efeitos negativos do processo de urbanização (DUARTE et al., 2008; ALVES, 2012). Portanto, torna-se necessário o planejamento e a implementação da arborização urbana nas cidades brasileiras com base não só em seus valores estéticos, mas nos serviços ecossistêmicos que ela desempenha para a melhoria da qualidade 
ambiental urbana.

Apesar de sua importância como um elemento essencial à paisagem urbana, a arborização urbana no Brasil ainda é um desafio a ser superado. A falta de políticas de valorização da arborização urbana na maior parte das cidades brasileiras, a escassez de ações públicas e privadas voltadas ao incremento da arborização urbana com o objetivo de melhorar a qualidade ambiental urbana, bem como a escassez de estudos científicos e corpo técnico especializado para orientar a arborização urbana de acordo com as necessidades e especificidades locais são alguns dos aspectos que demonstram a necessidade emergente de avanços nesta área.

Para compreender os aspectos atuantes na presente realidade, propôsse inicialmente a realização de uma breve reconstituição histórica do processo de arborização urbana no Brasil, buscando retratar como a mesma foi historicamente praticada. Posteriormente, buscou-se retratar o panorama atual da arborização urbana no Brasil, analisando a existência de iniciativas voltadas à valorização da arborização urbana, bem como os conflitos existentes ao seu acesso igualitário entre as classes sociais. A partir desta análise, o presente estudo busca compreender quais os reais desafios a serem superados para o incremento da arborização urbana no Brasil.

\section{BREVE HISTÓRICO DA ARBORIZAÇÃO URBANA NO BRASIL}

As primeiras iniciativas voltadas à arborização urbana no Brasil datam do século XVIII, com a implementação de hortos botânicos com caráter científico dada a necessidade de buscar conhecimentos a respeito da flora nativa ainda pouco conhecida. Ao mesmo tempo, estes hortos botânicos possuíam uma finalidade econômica ao buscar plantas úteis ao comércio de especiarias na Europa e ampliar o conhecimento sobre novas variedades nativas que pudessem competir com as culturas tradicionais cultivadas no Oriente (SEGAWA, 1996).

Até a segunda metade do século XIX, tanto a arquitetura quanto os jardins existentes no Brasil, sofriam grande influência dos padrões europeus (ARAGÃO, 2008). O padrão urbanístico português reproduzido no Brasil, até então, não 
considerava a arborização como um elemento da paisagem urbana.

Neste período, prevalecia a identificação de que a flora pertencia a ambientes rurais, enquanto ambientes urbanos eram considerados locais civilizados, portanto, livres de natureza (SEGAWA, 1996; TERRA et al., 2004; SILVA, 2013). Portanto, a introdução da vegetação nas cidades coloniais se deu num tímido processo em que a árvore era um elemento muito mais circunscrito à paisagem natural do que à organizada pelo homem. (TERRA et al., 2004)

O modelo urbanístico europeu consistia em ruas estreitas, traçados irregulares, ausência de calçadas, construções geminadas sem recuo frontal (ARAGÃO, 2008). Portanto, o traçado urbano nas cidades coloniais por não ser projetado para acolher a vegetação de porte arbóreo, tornou-se um empecilho para a prática da arborização urbana neste período (ARAGÃO, 2008; VIGNOLA JUNIOR, 2015).

De acordo com Aragão (2008), as ruas das cidades coloniais passam adquirir status social ainda no século XIX. Com isso, estes espaços públicos foram adaptados com lampiões e postes de iluminação, surgindo a partir de então, os primeiros exemplares arbóreos alinhados ao longo do calçamento.

Os jardins urbanos, até o século XIX, assumiam funções meramente estéticas, embelezadoras da paisagem, sendo considerados uma expressão de arte. Entretanto, neste período os jardins urbanos passam a assumir uma função utilitária, sobretudo nas zonas urbanas densamente povoadas, sendo-lhes atribuídos fins higiênico-sanitários, de incremento da qualidade ambiental, funcionalidades ecológicas e aspectos psicossociais (ANGELIS et al., 2005).

A disciplina urbanística e o salubrismo determinaram a necessidade de criar "pulmões" para as cidades, com a implantação de praças, jardins e parques no meio urbano. De acordo com Segawa (1996), a cultura salubrista foi a responsável pela manutenção de grandes áreas livres no coração das cidades num momento em que a expansão urbana demandava e valorizava as terras nas regiões centrais dos núcleos urbanos.

Em 1810, o marquês de Aguiar, ministro de dom João, ao regulamentar a expansão urbana do Rido de Janeiro, estabeleceu que a arborização urbana, não só embelezava a cidade, mas contribuía muito para a saúde da população. Seguawa (1996) estabelece que a cultura do salubrismo no século XIX contribuiu muito para 
novas funções da vegetação associada aos espaços urbanos.

Nesse momento, várias cidades brasileiras tratavam de "embelezar" (um termo da época) seus logradouros públicos segundo essa visão salubrista. O Rio de Janeiro do final do século 19, juntamente com as transformações promovidas por Pereira Passos a partir de 1904, e Belém com a ação do intendente Antonio Lemos estão entre as mais eloquentes iniciativas para o estabelecimento dessa visão, com a contribuição significativa da vegetação como elemento urbano, dentro de um novo espírito "civilizador" (SEGUAWA, 1996, p. 221).

Neste cenário, tem-se a primeira iniciativa voltada a estipular regras para a arborização de ruas no Brasil: "Acto" no 7, de 28 de março de 1896, decretado pelo então intendente municipal de polícia e "hygiene" de São Paulo, dr. José Roberto Leite Penteado. Esta iniciativa tinha como objetivo estimular a participação dos munícipes paulistanos na arborização da cidade (VIGNOLA JUNIOR, 2015).

A partir da segunda metade do século XIX, começa a popularizar-se o entendimento de que a existência de arborização de ruas nas cidades é de vital importância na qualidade ambiental nos espaços urbanos (VIGNOLA JUNIOR, 2015). Já ao longo do século XX tem-se a implantação de diversos parques urbanos com a fundamental contribuição de Roberto Burle Marx para o paisagismo no Brasil (TERRA et al., 2004).

Nos parques projetados por Burle Marx, as árvores eram tidas como elemento central, com destaque para o parque do Flamengo no Rio de Janeiro, que se tornou um dos projetos mais emblemáticos de Burle Marx. A concepção de parque urbano de Burle Marx era totalmente inovadora para a época, mesclando duas grandes vias expressas de ligação centro-sul com a oferta de áreas de recreação, esportivas, culturais e de lazer contemplativo, por meio de uma vegetação predominantemente nativa, disposta em novos arranjos, com árvores e palmeiras de formas e florações exuberantes, que levam a outra relação com o usuário (TERRA et al., 2004).

Tendo em vista que a arborização urbana é uma prática relativamente nova no Brasil (tendo-se as primeiras iniciativas há pouco mais de 120 anos), cabe ressaltar que, neste período a arborização foi historicamente praticada de forma empírica e, raras às vezes, dentro de um contexto técnico-científico (SILVA, 2013). 


\section{PANORAMA ATUAL DA ARBORIZAÇÃO URBANA NO BRASIL}

Atualmente, não existem estudos voltados ao conhecimento da arborização urbana que abranjam todo o território nacional. A maior parte dos estudos sobre arborização urbana no Brasil tem se atido ao levantamento da arborização no nível local, ou seja, bairros, conjunto de bairros ou mesmo a área urbana de um município.

Ademais, a expressiva maioria dos estudos sobre arborização urbana tem se concentrado no emprego de índices de cobertura vegetal apenas como indicador de presença ou ausência das áreas verdes, estabelecendo se a área de estudo está dentro do recomendado ou não (COSTA, 2009). Além disso, a falta de consenso no emprego de métodos e conceitos nos estudos sobre arborização urbana no Brasil, bem como suas dimensões continentais e diversidade de climas e biomas são alguns dos elementos que dificultam uma visão ampla de como a arborização urbana tem sido praticada no país (NUCCI; CAVALHEIRO, 1999).

A partir da coleta de dados do Censo Demográfico do ano de 2010, o IBGE lançou informações referentes às características urbanísticas do entorno dos domicílios, abrangendo áreas urbanas em todo o território nacional. As características observadas na coleta de dados dizem respeito à identificação dos logradouros, iluminação pública, pavimentação, arborização nos logradouros públicos, bueiro/ boca de lobo, lixo acumulado em vias públicas, esgoto a céu aberto, meio-fio/guia, calçada e rampa para cadeirante (IBGE, 2010).

As informações referentes à arborização, disponibilizadas pelo IBGE (2010), dizem respeito ao percentual de domicílios com presença de árvores sobre as calçadas. Estas informações inéditas, nesta escala de amplitude, são fundamentais para se obter um conhecimento mais profundo sobre a realidade atual da arborização urbana no Brasil.

O relatório sobre as características urbanísticas no entorno dos domicílios revelaram profundas diferenças no acesso à arborização urbana entre as regiões do Brasil. Desta forma, as regiões Sul e Sudeste obtiveram um percentual de $72,1 \%$ e $73,5 \%$ respectivamente, já as regiões Norte e Nordeste apresentaram percentuais de $36,7 \%$ e $61,5 \%$, respectivamente (IBGE, 2010). 


\subsection{CONFLITOS E INJUSTIÇA AMBIENTAL NA ARBORIZAÇÃO URBANA NO BRASIL}

Muito embora, ainda não haja uma profunda compreensão sobre os fatores responsáveis pela diferença entre os percentuais de arborização no entorno dos domicílios obtidos entre as regiões brasileiras, estas diferenças podem estar relacionadas à diferença no acesso à infraestrutura urbana entre estas regiões. Portanto, comparando os percentuais de arborização urbana aos percentuais de incidência de extrema pobreza, também disponibilizado pelo IBGE (2010), verificase que as regiões Sul e Sudeste obtiveram os maiores percentuais de arborização urbana, em contrapartida, os menores percentuais de incidência de extrema pobreza (2,53 e 3,76, respectivamente). Nesta mesma dinâmica, as regiões Norte e Nordeste obtiveram os menores percentuais de arborização urbana, e os maiores percentuais de incidência de extrema pobreza (14,41\% e 18,35\%, respectivamente).

Henrri, Campello e Bezerra (2008) conceituam injustiça ambiental como a desigualdade na distribuição, tanto dos benefícios como dos agravantes proporcionados pelo meio ambiente entre os diferentes grupos sociais. Neste sentido, Coelho (2013) afirma que, no Brasil, as populações de menor poder aquisitivo dispóem de menos acesso a recursos ambientais importantes para a qualidade ambiental urbana como a arborização. Ademais, Salles, Grigio e Silva (2013) argumentam que, geralmente, as áreas de degradação ambiental nas cidades coincidem com as áreas de degradação social, ampliando ainda mais seus efeitos e danos, caracterizando-se um cenário de injustiça ambiental.

Nesta perspectiva, a análise dos dados sobre a arborização urbana no Brasil, deixa bastante evidente que a mesma tornou-se mais um elemento de segregação socioespacial, à medida que seu maior acesso é proporcional à renda média e as condições da moradia (IBGE, 2010). Outrossim, Angeoletto e Santos (2015) apontam que, geralmente, os bairros com maior status socioeconômico apresentam maior diversidade vegetal, tanto nos espaços livres, como nos próprios quintais das residências.

Atualmente, o parcelamento do solo urbano, no Brasil para implantação de loteamentos para as classes sociais mais carentes, tem apresentado dimensões que variam entre 200 e $250 \mathrm{~m}^{2}$, com ruas e calçadas estreitas para diminuir os custos 
do empreendimento. Estas dimensões, além de dificultar o acesso da população ao verde urbano, a arborização se torna um problema para fiação elétrica e acessibilidade nas calçadas, aumentando ainda mais os conflitos e a desigualdade na qualidade ambiental urbana usufruída entre as classes sociais.

\subsection{LEGISLAÇÃO URBANA}

O Estatuto das Cidades (lei 10.257/2001) tem como objetivo estabelecer o desenvolvimento das funções sociais das cidades e da propriedade urbana, adequando o uso da propriedade urbana ao bem da coletividade, resguardando os direitos fundamentais e também o equilíbrio ambiental. Embora a arborização urbana seja um elemento fundamental para o equilíbrio ambiental nos ambientes urbanizados, o Estatuto das Cidades deixa a cargo dos municípios e seus respectivos planos diretores legislar e gerir a arborização urbana, criando seus próprios instrumentos.

Ao deixar a gestão da arborização a cargo dos municípios, sem oferecer instrumentos norteadores, estabelecer parâmetros mínimos aceitáveis, ou mesmo oferecer uma classificação de arborização urbana, favorece que cada cidade planeje a arborização urbana de acordo com seus próprios critérios. Neste sentido, estabeleceuse uma verdadeira confusão na utilização de conceitos, muitas vezes empregados erroneamente, que dificultam ou impossibilitam a realização de comparativos entre municípios (NUCCI; CAVALHEIRO, 1999).

Neste cenário, enquanto algumas poucas cidades brasileiras possuem uma legislação específica sobre a arborização urbana bem estruturada e planejada para melhorar a qualidade ambiental urbana, a expressiva maioria das cidades brasileiras sequer possui algum tipo de controle sobre a arborização urbana (IBGE, 2010).

A falta de estrutura é uma realidade em muitas prefeituras, dificultando a execução de ações de fiscalização, fazendo com que, mesmo as cidades que possuam leis específicas, pela falta de fiscalização, estas leis não sejam de fato aplicadas. Neste sentido, embora o Estatuto das Cidades definam um percentual de área destinada para áreas verdes nos loteamentos implantados, é comum que estas áreas só existam nos projetos, ou mesmo, estejam completamente degradadas pela falta de 
manutenção, não contribuindo para a melhoria da qualidade ambiental nestes locais (DUARTE, 2016).

\section{CONSIDERAÇÕES FINAIS}

Ainda existem muitos desafios a serem superados para que a arborização urbana no Brasil seja considerada satisfatória, no sentido de proporcionar maior qualidade ambiental à população urbana. Dentre estes desafios, podem-se apontar maiores investimentos em infraestrutura e planejamento urbano voltado ao incremento da arborização urbana, maior valorização da arborização urbana como elementos essenciais à paisagem urbana, investimentos em capacitação de profissionais junto às secretarias municipais de meio ambiente e distribuição mais igualitária da flora urbana e de seus serviços ecossistêmicos entre bairros de diferentes classes sociais nas cidades brasileiras.

A falta de planejamento da urbanização introduz elementos hostilizadores à prática da arborização urbana, como calçadas estreitas, vias não projetadas ao plantio de árvores, rede elétrica, fachadas de empreendimentos comerciais, cercas elétricas, dentre outros. Portanto, as ações voltadas ao incremento da arborização urbana no Brasil para melhoria da qualidade ambiental urbana devem priorizar o investimento em infraestrutura urbana anteriormente planejada para sua introdução.

A falta de valorização dada à arborização urbana no planejamento urbano no Brasil tem suas raízes históricas no modelo urbanístico da colonização portuguesa. Atualmente, sua desvalorização é decorrente de fatores sociais, econômicos e até mesmo pela falta de conhecimento sobre os benefícios e importância das árvores no meio urbano. Neste cenário, apenas algumas poucas cidades se destacam pela arborização urbana bem planejada, enquanto a maior parte das cidades brasileiras nem sequer possuem leis específicas ou corpo técnico especializado para o planejamento, execução e fiscalização da arborização urbana.

Muito embora a legislação brasileira esteja muito aquém do necessário para garantir a implementação da arborização urbana no Brasil, é comum que elas não sejam de fato aplicadas pela falta de fiscalização por parte dos órgãos responsáveis. 
Desta forma, as ações de fiscalização são tão importantes quanto o planejamento, para o incremento da arborização urbana nas cidades brasileiras.

Pode-se, ainda, afirmar que ao priorizar investimentos em infraestrutura urbana nos bairros mais carentes, pode-se proporcionar uma distribuição mais equânime da arborização urbana e de seus serviços ecossistêmicos entre as diferentes classes sociais, diminuindo a desigualdade social no acesso à arborização urbana nas cidades brasileiras.

\section{REFERÊNCIAS}

ALBUQUERQUE, M. M.; LOPES, W. G. R. Influência da vegetação em variáveis climáticas: Um estudo em bairros da cidade de Teresina, Piauí. Espaço Geográfico em Análise, Curitiba, v. 36, p. 38-68, Abril 2016.

ALVES. D.B. Cobertura vegetal e qualidade ambiental na área urbana de Santa Maria RS. 2012. 155f. Dissertação (mestrado) - Universidade Federal de Santa Maria, Santa Maria, RS.

ANGEOLETO, F. H. S.; SANTOS, J. W. M. C. Los biólogos brasileños no habitan en el planeta ciudad por qué es urgente formar ecólogos urbanos. Revista Espaço Acadêmico, n.165, 2015.

ANGEOLETTO, F.; SANTOS, J.W.M.C.; SANZ, J.P.R.; SILVA, F.F.; ALBERTÍN, R.M. Tipologia socio-ambiental de las ciudades medias de Brasil: aportes para um desarrollo urbano sostenible. Urbe Revista Brasileira de Gestão Urbana, v. 8, n. 2, p. 272-287, 2016.

ARAGÃO, S. Em Tempo de Histórias. Brasília: Publicação do Programa de PósGraduação em História PPG-HIS/UnB, 2008. n.12.

ARIZA, G.; SANTOS, D. G. Qualidade ambiental e planejamento urbano. Caminhos da Geografia, Uberlância, v. 9, n. 26, p. 224-242, Junho 2008.

BRASIL. Lei 10.257/2001 de 10 de Julho de 2001. Estatuto das cidades. Brasília, Diário Oficial de 11/07/2001.

COELHO, M. C. N. Impactos ambientais em áreas urbanas: Teorias, conceitos e 
métodos de pesquisa. In: GUERRA, A. J. T.; CUNHA, S. B. Impactos ambientais urbanos no Brasil. 10. ed. Rio de Janeiro, 2013.

COSTA, R. G. S.; FERREIRA, C. C. M. Análise do índice de áreas verdes (IAV) na área central da cidade de Juiz de Fora, MG. Revista Brasileira de Arborização Urbana, Piracicaba, v. 4, n. 1, p. 39-57, 2009.

CRETELLA, A.; BUENGER, M. S. Food as creative city politics in the city of Rotterddam. Cities, v. 51, p. 1-10, 2016.

CUBINO, J.P.; LOZANO, C.B.; SUBIRÓS, J.V. Plant biodiversity and city: approaches from urban ecology. Boletín de la Asociación de Geógrafos Españoles. n. 68, p. 465 a 471, 2015.

DE ANGELIS, B.L.; DE ANGELIS NETO, G.; BARROS, G.A.; BARROS, R.A.; SCHIAVON, V.S. Da jardinagem ao paisagismo: evolução histórica. Maringá, PR: EUDEM, 2005.

DUARTE, F. G.; SANTOS, A.G.; ROSADO, F.R.; DELARIVA, R.L.; SAMPAIO, A.C. Cupins (Insecta: Isoptera) na arborização urbana da Zona 1 de Maringá - PR. Revista em Agronegócio e Meio Ambiente, Maringá, v. 1, n. 1, p. 87-99, janeiro/abril 2008.

DUARTE, T.E.P.N. Expansão urbana e qualidade ambiental: uma análise da cobertura vegetal urbana em Rondonópolis entre os anos de 2006 e 2015. 2016. Dissertação (Mestrado em Geografia) - UFMT, Rondonópolis, MT.

EMBRAPA. Arborização urbana e produção de mudas de essências florestais nativas em Corumbá, MS. Corumbá: Embrapa Pantanal, 2002.

GOMES, M. A. S.; SOARES, B. R. Reflexões sobre qualidade ambiental urbana. Estudos Geográficos, Rio Claro, v. 2, n. 2, p. 21-30, julho/dezembro 2004.

HENRI, A.; CAMPELLO, M.C.; BEZERRA, G.N. O que é justiça ambiental. [s.l.]: Garamond, 2008.

INSTITUTO BRASILEIRO DE GEOGRAFIA E ESTATÍSTICA - IBGE. Características urbanísticas do entorno dos domicílios. Rio de Janeiro: IBGE, 2010. p. 1-175.

LOCKE, D. H. et al. Applications of urban tree canopy assessment and prioritizations tools: Supporting collaborative decisions making to achieve urban sustainability 
goals. Urban Forestry Practitioners, v. 6, p. 1-26, 2013.

LOCKE, D.; BAINE, G. The good, the bad, and the interestede: How historical demographics explain present-day tree canopy, vacant lot and tree request spatial variability in New Haven, CT. Urban Ecosyst, New York, v. 18, p. 391-409, setembro 2015.

LOURENÇO, F. A. et al. Metrópolis, cobertura vegetal, áreas verdes e saúde. Estudos Avançados, v. 30, p. 113-130, 2016.

MAGALHÃES, L. M. S. Arborização e florestas urbanas: terminologia adotada para a cobertura arbórea das cidades brasileiras. Floresta e Ambiente, Janeiro/2006, p. 23-26.

MAZETTO, D. A. P. Qualidade de vida, qualidade ambiental e meio ambiente urbano: Breve comparação de conceitos. Sociedade \& Natura, Uberlância, v. 12, n. 24, p. 21-31, Julho/Dezembro 2000.

MINAKI, C.; AMORIM, M. C. D. C. T. Análise da qualidade ambiental urbana. Mercator, Fortaleza, v. 11, n. 34, p. 229-251, Janeiro/Abril 2012.

MOTA, S. Urbanização e meio ambiente. Rio de Janeiro: ABES, 1999.

NUCCI, J. C. Qualidade ambiental e adensamento urbano: um estudo de ecologia e planejamento da paisagem aplicado ao distrito de Santa Ceć́lia (MSP). 2. ed. Curitiba: [s.n.], 2008. 142p.

NUCCI, J. C.; CAVALHEIRO, F. Cobertura vegetal em áreas urbanas - conceito e método. GEOUSP, São Paulo, n. 6, p. 29-36, 1999.

RAHMAN, M. A.; ARMSON, D.; ENNOS, A. R. A comparison of the growth and cooling effectiveness of five commonly planted urban tree species. Urban Ecosyst, v. 18, p. 371-389, 2014.

SALLES, MCT; GRIGIO, AM; SILVA, MRF. Expansão urbana e conflito ambiental: uma descrição da problemática do município de Mossoró, RN - Brasil. Soc. \& Nat., Uberlândia, v. 25, n. 2, p. 281-290, maio/ago 2013.

SAMPAIO, A. C. Análise da arborização de vias públicas das principais zonas do 
plano piloto de Maringá - PR. 2006. Dissertação (mestrado em Geografia) - UEM, 2006.

SECRETARIAT OF THE CONVENTION ON BIOLOGICAL DIVERSITY. Cities and Biodiversity Outlook. Montreal: [s.n.], 2012. 64 p.

SEGAWA, H. Ao amor do público: jardins no Brasil. São Paulo: Studio Nobel, 1996.

SILVA, M. C. Arborização urbana de quatro cidades do leste de Mato Grosso do Sul. 2013. 63f. Dissertação (mestrado em Geografia) - Universidade Federal de Goiás, Jataí, GO.

SOUZA, M. C. D. C.; AMORIM, M. C. C. T. Qualidade ambiental em áreas verdes públicas na periferia de Presidente Prudente SP: os exemplos dos bairros Humberto Salvador e Morada do Sol. Caminhos de Geografia, Uberlânia, v. 17, n. 57, p. 59-73, Março 2016.

TERRA, C.; ANDRADE, R.; TRINDADE, J; BENASSI, A. Arborização: ensaios historiográficos. Rio de Janeiro: Maia Barbosa, 2004. 215p.

TIAN, Y.; JIM, C.Y.; TAO, Y.; SHI, T. Landscape ecological assessment of green space fragmentation in Hong Kong. Urban Forestry \& Urban Greening, v. 10, p.7986. fev. 2011.

VELÁZQUEZ, G. Á.; CELEMÍM, R. P. Aplicación de un índice de calidad ambiental a la región pampeana argentina. Finisterra, Lisboa, v. 6, n. 91, p. 47-64, 2010.

VIGNOLA JUNIOR, R. ArbVias: método de avaliação da arborização no sistema viário urbano. Paisagem e Ambiente, São Paulo, v.1, n. 35 p.89-117, 2015.

Recebido em: 2016-04-01 Aceito em: 2017-03-05 